\title{
The Effect of Grain Boundary Carbides on Dynamic Recrystallization During Hot Compression of Ni-Based Superalloy Haynes $282^{\mathrm{TM}}$
}

\author{
EMIL ERIKSSON, JOEL ANDERSSON, and MAGNUS HÖRNQVIST COLLIANDER \\ In alloys where carbides are the main grain boundary phase, the role of carbides during hot \\ working is not known. Here, we address the effect of grain boundary carbides on the dynamic \\ recrystallization during hot compression of Ni-base superalloy Haynes 282. When excluding \\ variations from experimental factors neither stress evolution nor final microstructure indicated \\ that carbides exerted a significant influence on the dynamic recrystallization. The carbide solvus \\ temperature is not a critical limit during thermomechanical processes.
}

https://doi.org/10.1007/s11661-021-06524-x

(C) The Author(s) 2021

NI-BASE superalloys offer excellent combinations of mechanical properties at high temperatures together with microstructure stability and resistance to oxidation and corrosion, making them suitable for applications in the hot sections of jet engines and gas turbine generators. ${ }^{[1]}$ The mechanical properties are derived from the microstructure of the alloy, which is in turn controlled by thermomechanical processing and heat treatments. During high temperature processing the thermal energy can activate numerous phenomena such as dynamic recovery (DRV), discontinuous and/or continuous recrystallization (dDRX and/or cDRX), meta dynamic recrystallization (mDRX) and post dynamic recrystallization (pDRX). ${ }^{[2-6]}$ The contribution of these processes to formation of the final microstructure is complex, and affected by many factors such as alloying content, phase distribution in the alloy, initial microstructure, deformation temperature and applied strain and strain rate. ${ }^{[7,8]}$ For Ni-base superalloys dDRX is the most common recrystallization process, which is attributed to the decreased possibility of dislocations to cross slip due to the relatively low stacking fault energies (SFE) ${ }^{[2]}$ Typical of dDRX is the serrations/bulging of the grain boundaries, which act as nucleation sites for new grains, ${ }^{[4]}$ and a pronounced development of annealing twins during the growth of the grains. ${ }^{[9]}$

E. ERIKSSON and M. HÖRNQVIST COLLIANDER are with the Department of Physics, Chalmers University of Technology, Fysikgränd, 3, 41296 Göteborg, Sweden. Contact e-mail: emil.eriksson@chalmers.se. J. ANDERSSON is with the Univeristy West, Gustava Melins Gata 2, 461 32, Trollhättan, Sweden.

Manuscript submitted September 8, 2021; accepted October 29, 2021.

Article published online November 15, 2021
In many superalloys with intermetallic grain boundary phases such as $\delta$ or $\eta$, e.g., Alloy 718 and Allvac 718Plus, respectively, deformation below the solvus temperature is commonly used to control the recrystallization and grain growth during processing. ${ }^{[10]}$ For alloys containing secondary carbides as dominating grain boundary phases, less work has been done to understand the possible effects on the microstructural development during hot deformation. As mentioned above, dDRX usually occurs though bulging of grain boundaries at subgrains formed during deformation. It could therefore be suspected that the presence of carbides, which essentially cover the entire grain boundary area, could affect the nucleation stage by (i) altering the dislocation substructure in the vicinity of the boundaries and thereby the subgrain formation process; and/or (ii) by pinning the boundaries during bulging (so called Zener pinning), which has been shown to increase the length of the boundary involved in the bulging process during static recrystallization, thereby delaying nucleation. ${ }^{[11]}$ Consequently, grain boundary carbides could play a decisive role in the design of hot working processes, and thereby in the need for precise temperature control. However, while the effect of particle stimulated DRX nucleation at primary carbides in coarse grained material has received some attention (see e.g., ${ }^{[12]}$, the role of grain boundary carbides during DRX of Ni-base superalloys has not been previously reported.

In this study we address the effect of grain boundary carbides on the DRX processes during hot compression of Haynes 282 (H282). This is a relatively new, $\gamma^{\prime}$ strengthening superalloy with high fabricability and weldability. ${ }^{[13]}$ The alloy consists of an disordered FCC matrix, $\gamma$, with strengthening precipitates of ordered $\mathrm{L}_{2}$ $\mathrm{Ni}_{3}(\mathrm{Ti}, \mathrm{Al}) \gamma^{\prime}$. Large intergranular primary MC carbides form during the remelting of the ingots, and remain 
stable throughout subsequent processing steps. Secondary $\mathrm{M}_{23} \mathrm{C}_{6}$ and $\mathrm{M}_{6} \mathrm{C}$ carbides are precipitated at temperatures below the carbide solvus $\left(1100{ }^{\circ} \mathrm{C}\right)$ and exist primary at grain boundaries, ${ }^{[14,15]}$ improving the ductility creep resistance.

A previous study Reference 16, showed that hot deformation of $\mathrm{H} 282$ below the grain boundary carbide solvus was efficient for creating a fine grained microstructure, but whether this was related to the presence of carbides or purely an effect of the lower deformation temperature could not be concluded as all tested samples were soaked below the carbide solvus prior to deformation, i.e., grain boundary carbides where present in all starting conditions. In order to isolate the possible effects of grain boundary carbides on DRX in H282, we perform dedicated tests above and below the solvus temperature. Specifically, we test specimens soaked above, but tested below, the carbide solvus to compare the DRX behavior with and without (or at least with minimum amount of) grain boundary carbides present. The study shows that although minor effects can be seen, the presence of carbides does not exert a significant influence on the mechanical response or microstructure formation during hot compression. Instead, the deformation temperature is the deciding factor for controlling the grain size, independent of the presence or absence of carbides. This suggests that although accurate temperature control during processing is essential to obtain the desired microstructure, the carbide solvus does not have to be considered as a critical limit.

H282, with chemical composition shown in Table I, was received as cylindrical slices from a billet, with thickness of $15 \mathrm{~mm}$ and a diameter of $152 \mathrm{~mm}$ (6 inches) with a microstructure typical for industrial forging operations. Cylindrical samples for hot compression (12 $\mathrm{mm}$ in height and $8 \mathrm{~mm}$ in diameter) were machined from the billet slice. In order to ensure similar microstructure in all samples they were machined at the same radial position (half the radius) in the slice.

Two sets of samples were subjected to hot compression tests at $1080{ }^{\circ} \mathrm{C}$ (below the secondary carbide solvus) in a Gleeble 3800 thermomechancial simulator. The first set, hereafter denoted "C" (as in carbides) was subjected to a pre-deformation soaking at the deformation temperature for 30 minutes to stabilize the grain boundary carbide structure. The second set, denoted "NC' (no carbides) was instead soaked at $1120{ }^{\circ} \mathrm{C}$ for 30 minutes prior to deformation, in order to produce a structure with carbide free grain boundaries. Soaking was performed in a muffle furnace in atmospheric environment and the samples were water quenched. The samples were subsequently heated to $1080{ }^{\circ} \mathrm{C}$ at a rate of $17^{\circ} \mathrm{C} \mathrm{min}{ }^{-1}$ (total heating time 60 seconds) in the Gleeble, left to stabilize for 10 seconds and then compressed to a nominal true strain (i.e., calculated based on the assumption of homogeneous deformation) of 0.8 at three different strain rates, 0.05 second $^{-1}, 0.5$ second $^{-1}$ and 5 seconds ${ }^{-1}$ at $1080{ }^{\circ} \mathrm{C}$ and directly water quenched. One additional NC sample was water quenched after the 10 second stabilization time (without compression) to determine the exact starting structure induced by the heating and stabilization. The two sets of tests are graphically shown in Figures 1(a) and (b). A third set of tests, shown in Figure 1(c), was also conducted, where the samples were soaked for 30 minutes at $1120^{\circ} \mathrm{C}$, before deformation at $1120^{\circ} \mathrm{C}$ with the same strain rate as previous procedures. These tests, denoted "S" (for supersolvus) served as references with a starting structure guaranteed to be free of grain boundary carbides and without possibility of dynamic precipitation. Since the $\gamma^{\prime}$ solvus is around 1010 ${ }^{\circ} \mathrm{C}$, no $\gamma^{\prime}$ was present in the samples.

The deformed samples were sectioned parallel to the compression axis, subjected to standard metallographic preparation and investigated using scanning electron microscopy (SEM) and electron backscatter diffraction (EBSD). A detailed description of the procedure for microstructural analysis has been presented elsewhere. ${ }^{[16]}$ To distinguish grain boundary carbides the samples were etched in a solution of $98 \% \mathrm{HCl}$ and $2 \%$ oxalic acid at $3 \mathrm{~V}$ for 3 to 5 second at room temperature. In order to get a better understanding of carbides after deformation, EDS maps of regions containing carbides on samples post deformation.

The microstructures of the soaked samples are presented in Figure 2. The structures are very similar, indicating that no significant grain growth or other microstructural changes, which should influence the comparison between the set $\mathrm{C}$ and set NC samples, occurred due to the different soaking temperatures. Average grain diameters were $58 \mu \mathrm{m}$ (after $1080{ }^{\circ} \mathrm{C}$ soak) and $62 \mu \mathrm{m}$ (after $1120{ }^{\circ} \mathrm{C}$ soak).

SE images of etched sample surfaces are shown in Figure 3. Grain boundary carbides are very clearly visible after soaking at $1080{ }^{\circ} \mathrm{C}$, Figures 3(a) and (d), while they completely dissolve when soaked at supersolvus temperatures, Figures 3(b) and (e). Please note that this is only the case at grain boundaries. Occasional carbides are still present intergranularly after the 1120 ${ }^{\circ} \mathrm{C}$ soak, Figure 3(b). However, during reheating to 1080 ${ }^{\circ} \mathrm{C}$ and 10 second temperature stabilization in the Gleeble, some precipitation of carbides occurred, as seen in Figures 3(c) and (f). This of course indicates that grain boundary carbides were present in both $\mathrm{C}$ and $\mathrm{NC}$ samples at the start of the compression, however, to a much smaller extent in the nominally carbide free $\mathrm{NC}$ condition. The grain boundary carbides nucleated on random HAGB and incoherent $\Sigma 3$ boundaries, whereas coherent $\Sigma 3$ boundaries did not contain any carbides. Larger primary carbides can also be seen, both intergranularly and occasionally at grain boundaries in all samples, as their solvus temperature lies above the temperatures investigated in this study.

The true stress-strain curves are shown in Figures 4(a) through (c). Here it should be noted that the true stress is calculated based on the same assumptions as the true strain, i.e., homogeneous deformation in the specimen. This assumption is not fulfilled due to inhomogeneous heating and frictional effects, see Reference 16 for a fuller discussion, but serve for relative comparison between samples. As can be seen, the mechanical behavior of specimens with and without carbides is very 
Table I. Chemical Composition (Wt Pct) of Haynes 282 According to Material Certificate

\begin{tabular}{|c|c|c|c|c|c|c|c|c|c|c|}
\hline $\mathrm{Ni}$ & $\mathrm{Cr}$ & $\mathrm{Co}$ & Mo & $\mathrm{Ti}$ & $\mathrm{Al}$ & $\mathrm{Fe}$ & $\mathrm{Mn}$ & & $\mathrm{C}$ & B \\
\hline Bal. & 19.3 & 10.2 & 8.7 & 2.2 & 1.5 & 0.9 & 0.05 & $<0.05$ & 0.06 & 0.004 \\
\hline
\end{tabular}

\section{Set C}

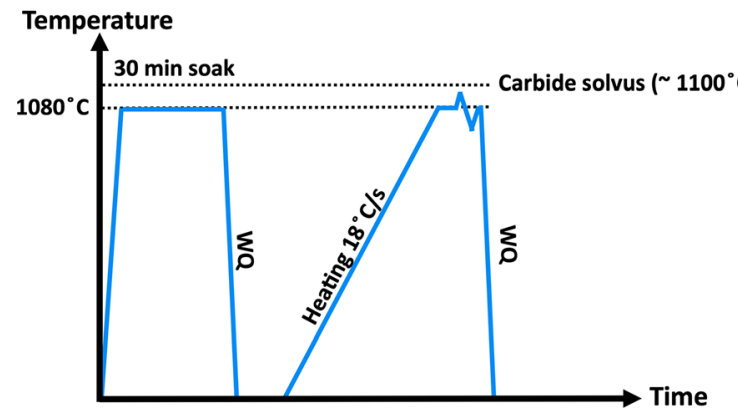

(a)
Set S

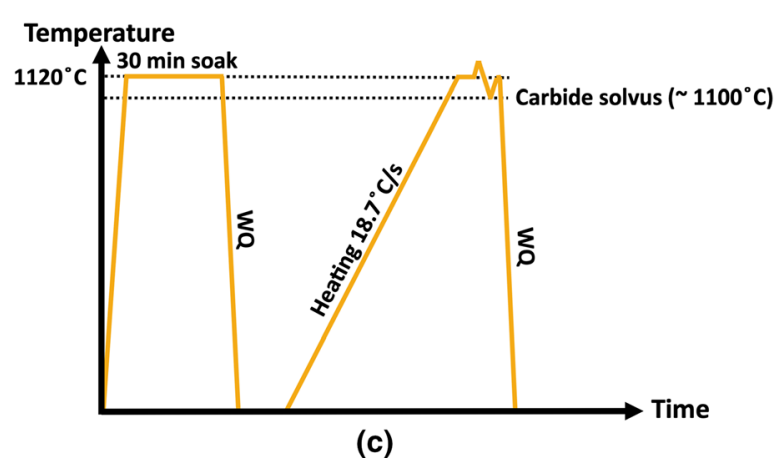

Set NC

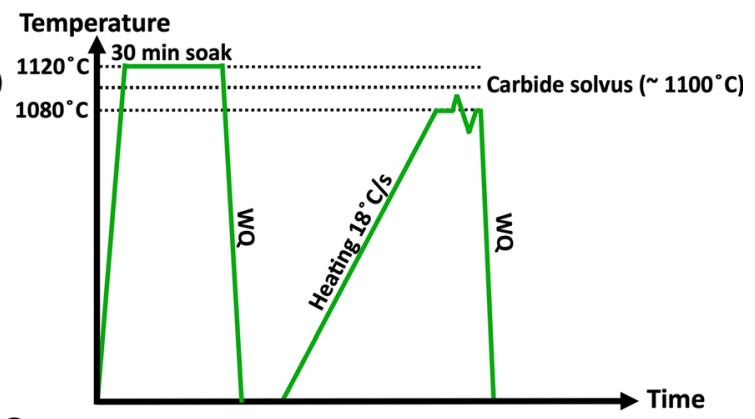

(b) structure with grain boundary carbides; (b) Set NC: Soaking at $1120{ }^{\circ} \mathrm{C}$ followed by deformation at $1080{ }^{\circ} \mathrm{C}$ to test structure without carbides at subsolvus temperature; $(c)$ Set S: Soaking and deformation at $1120^{\circ} \mathrm{C}$ to fully avoid any influence of grain boundary carbides.

similar during deformation at $1080{ }^{\circ} \mathrm{C}$. The differences in stress levels observed are in the order of 5-20 MPa, which is within the scatter observed in separate duplicate tests of nominally identical samples. However, the stresses are consistently higher in the material with carbides. This is presumably due to the consistently lower temperatures (by $1-5{ }^{\circ} \mathrm{C}$ ) in these samples, compared to samples without carbides. A closer inspection of the temperature evolution, Figures 4(d) through (f), shows that the temperatures in the NC samples were consistently around $1{ }^{\circ} \mathrm{C}$ higher already before the start of the deformation, and the difference subsequently increase during compression. This is presumably due to subtle differences in the Gleeble temperature control response, rather than a material effect, since the absence of carbides in the NC samples should result in less adiabatic heating, not more. The reason for this systematic difference is not clear at present, as the same temperature control sequence and thermocouple mounting was used in all cases. The stress response at $1120^{\circ} \mathrm{C}$ was noticeably different, with significantly lower stresses.
The evolution of temperature, was otherwise similar to the previously reported behavior during hot compression testing with the same conditions. ${ }^{[16]}$ Tests at 0.05 second $^{-1}$, Figure 4(d) shows initial adiabatic heating followed by stabilization. At 0.5 second $^{-1}$, Figure 4(e), the samples underwent initial adiabatic heating followed by cooling as the temperature control system attempted to compensate, leading to temperatures below target during the final part of the compression. During deformation at 5 seconds $^{-1}$, Figure 4(f), adiabatic heating continued to dominate throughout the test, leading to continuously increasing temperatures in spite of the complete stop of resistive heating (seen as dip in the temperature curves), which occurred before compression was complete due to the control mode of the Gleeble (heating was controlled in time and the acceleration/deceleration at the highest deformation rates caused the test time to be longer than intended).

From Figures 4(g) to (i) we also note that the so called quench delay, i.e., the time between the end of deformation (denoted by the dashed line) and the onset of the water quench (denoted by circles) varies 

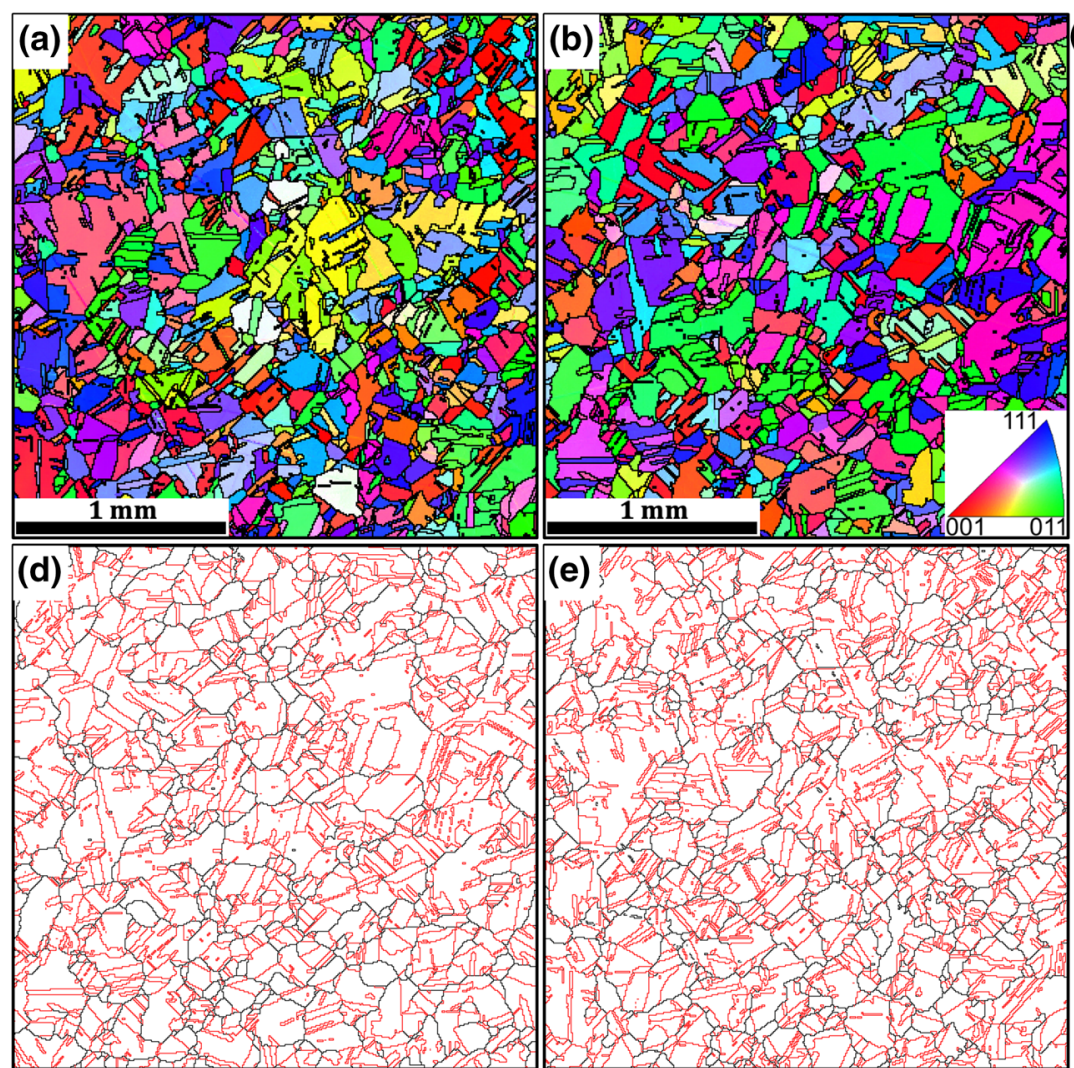

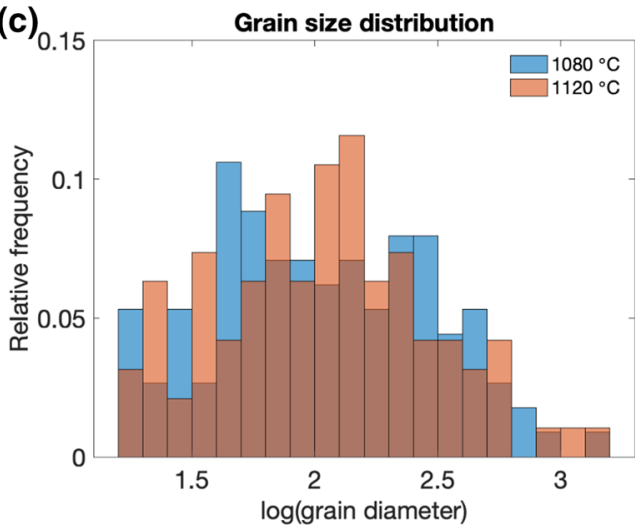

(f)

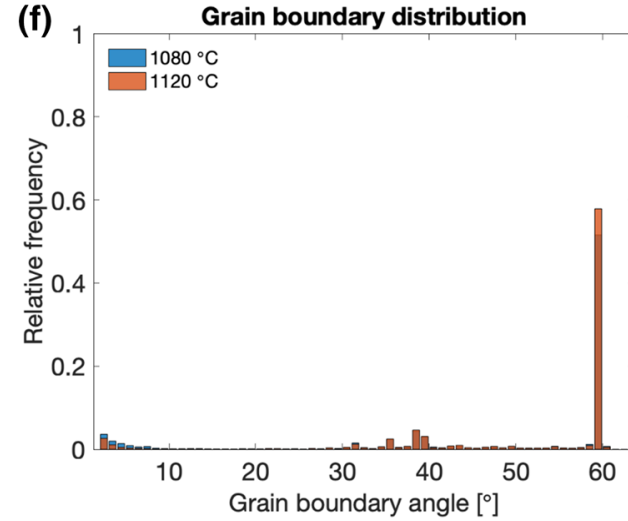

Fig. 2-Initial microstructure after soaking at 1080 and $1120{ }^{\circ} \mathrm{C}$. $(a)$ and $(d)$ show the IPF map and grain boundaries with HAGB (black lines correspond to a misorientation $>10^{\circ}$, red lines are $\Sigma 3 \mathrm{CSL}$ boundaries), respectively, after soaking for 30 min at 1080 circ $\mathrm{C}$. (b) and $(e)$ show the corresponding maps but after 30 min soaking at $1120{ }^{\circ}$ C. $(c)$ Grain size distribution on a $\log _{10}$ scale. $(f)$ Grain boundary misorientation distribution.

significantly between the tests, with the shortest being 0.13 second and the longest quench delay being 2.10 seconds. This is of particular importance for the tests at 5 seconds $^{-1}$, where the extent of the quench delay far exceeds the actual deformation time, although the temperatures are significantly below the deformation temperature due to conductive cooling. The quench delay cannot be more precisely controlled, but the observed difference must be kept in mind during further analysis of the recrystallized microstructures.

To summarize the observations, no significant difference in the hot deformation behavior of samples with and without carbides could be observed. Considering experimental uncertainties, the response of microstructures for set $\mathrm{C}$ and set $\mathrm{NC}$ was within the expected scatter.

Inverse pole figure (IPF) maps, acquired from a $500 \times$ $500 \mu \mathrm{m}^{2}$ area the center of the cross section, of all samples are shown in Figure 5. The microstructures after deformation at $1080{ }^{\circ} \mathrm{C}$ [Figures 5(a) through (f)] correspond well to those previously reported, ${ }^{[16]}$ with no distinct difference between set $\mathrm{C}$ and NC. Necklace structures with deformed grains surrounded by small DRX grains formed during dDRX (see Reference 16). After deformation at $1120^{\circ} \mathrm{C}$ the crystallization had progressed much further, see Figures 5(g) through (i). As can be seen from Figure 6(a) the average size of the recrystallized grains was very similar for samples with and without carbides when deformed at $1080{ }^{\circ} \mathrm{C}$, including a minimum at intermediate strain rates, in agreement with the previous study. ${ }^{[16]}$ Deformation at $1120^{\circ} \mathrm{C}$ produced microstructures with fewer remaining deformed grains and significantly larger average recrystallized grain sizes, without pronounced effects of strain rate.

A more detailed examination of the size distributions of the recrystallized grains [Figure 6(b), showing histograms of the logarithm of the grain size to resolve distribution of small grains], confirms the previous observation. There is a small shift towards larger sizes for the samples without carbides, but considering the slightly higher temperatures during deformation this is more likely a result of deformation conditions than an effect of grain boundary carbides. After deformation at 

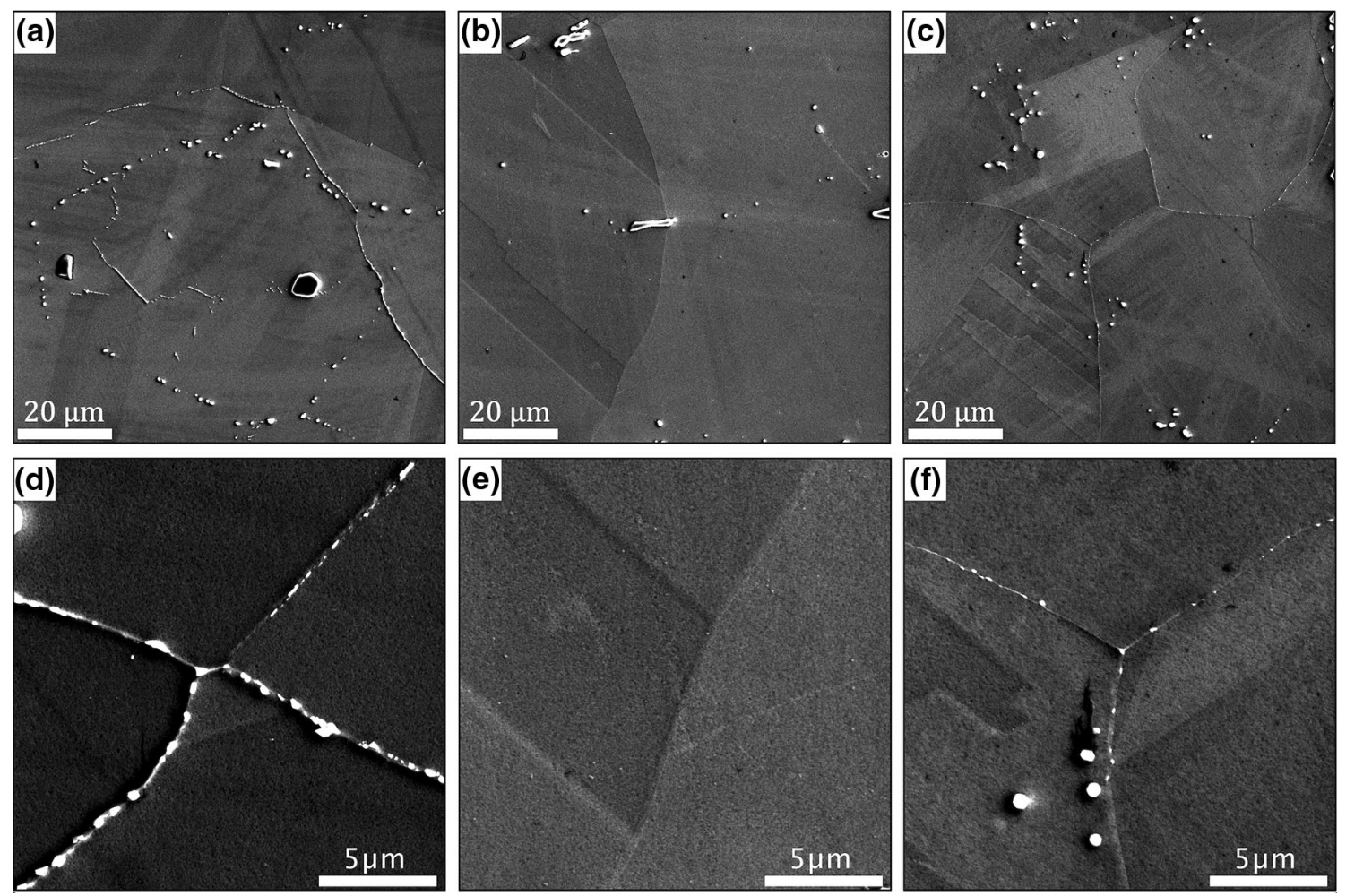

Fig. 3 - Carbide structures for each investigated condition. $(a, d)$ shows the microstructure after 30 min soaking at $1080{ }^{\circ} \mathrm{C}($ set $\mathrm{C}) ;(b, e)$ after a 30 min soaking at $1120^{\circ} \mathrm{C}$ (set S); and $(c, f)$ same as $(b, e)$ but subsequently heated to 1080 in the Gleeble, held for $10 \mathrm{~s}$ and quenched (set NC).

$1120^{\circ} \mathrm{C}$ the distribution is further shifted to larger sizes. Notably, the grain size appear to follow log-normal distributions. At 0.05 and 5 seconds $^{-1}$ the widths of the distributions at each strain rate are relatively constant, independent of soaking conditions and test temperature. At the intermediate strain rate, the distribution obtained after deformation at $1120{ }^{\circ} \mathrm{C}$ is similar to that obtained at higher and lower strain rates, whereas the distributions in samples deformed at $1080{ }^{\circ} \mathrm{C}$ are significantly narrower

Figure 6(c) shows the recrystallized fraction determined by a grain diameter threshold as previously described in Reference 16. The error bars symbolize the DRX fraction should the diameter threshold be set to 80 $\%$ or $150 \%$ of the selected values. The DRX fraction was consistent for samples with and without carbides deformed at $1080{ }^{\circ} \mathrm{C}$, with minima observed at 0.5 second $^{-1}$. At $1120{ }^{\circ} \mathrm{C}$, very high DRX fractions are observed, which agrees with observations from Figures $5(\mathrm{~g})$ through (i). Note that the DRX fractions determined based on grain size will produce a lower bound for the samples deformed at $1120{ }^{\circ} \mathrm{C}$, since the remaining deformed grains are much smaller which produces a larger overlap between the size distributions for the deformed and recrystallized grains. Separation of deformed and recrystallized grains based on grain orientation spread (GOS), was not possible due to the limited angular resolution and the fact that the fast DRX process allowed also the first recrystallized grains to undergo deformation during the later stage of testing. However, the absolute values of the DRX fractions for the samples deformed at $1120{ }^{\circ} \mathrm{C}$ is not critical for the analysis.

To summarize the microstructural observations, no significant differences between the samples with and without grain boundary carbides, beyond what could plausibly be explained by experimental factors such as temperature differences and variations in quench delay, could be seen. This indicates that the effects of grain boundary carbides on the DRX behavior of H282 is negligible.

Although the main objective of this study was to determine to what extent, if any, the grain boundary carbides affect the microstructure evolution during hot compression, a natural question is whether or not the carbides themselves are affected by the deformation.

Figure 7 shows a comparison of the microstructures after deformation at subsolvus temperatures. Figures 7(a) through (c) show secondary electron images of the etched surfaces of samples in set $C$, while 


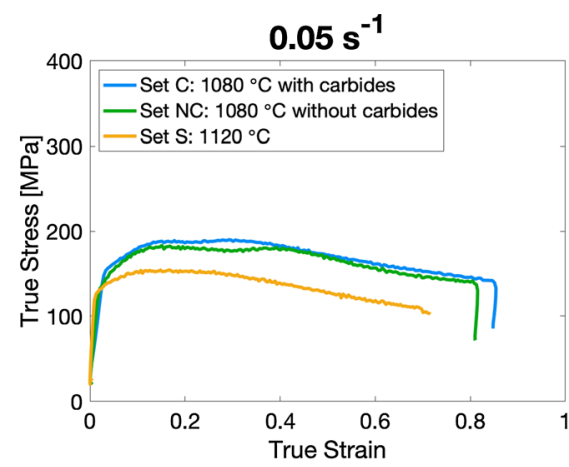

(a)

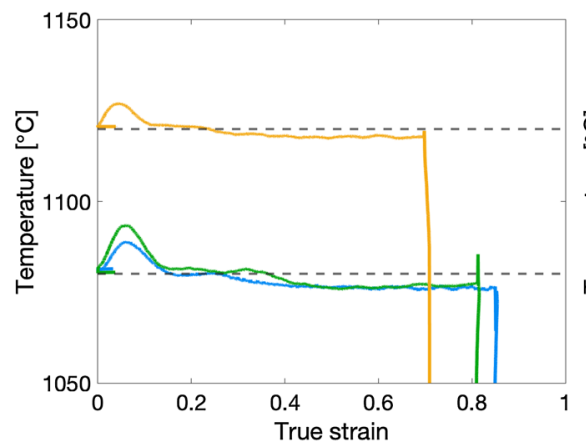

(d)

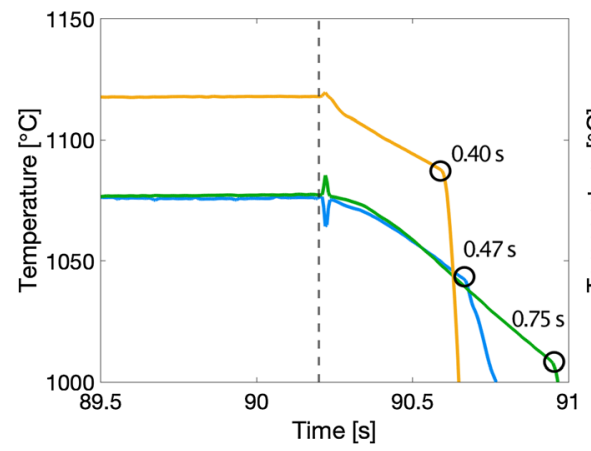

(g)

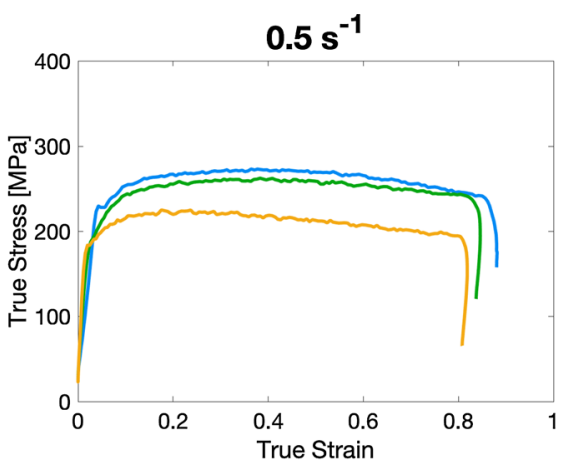

(b)

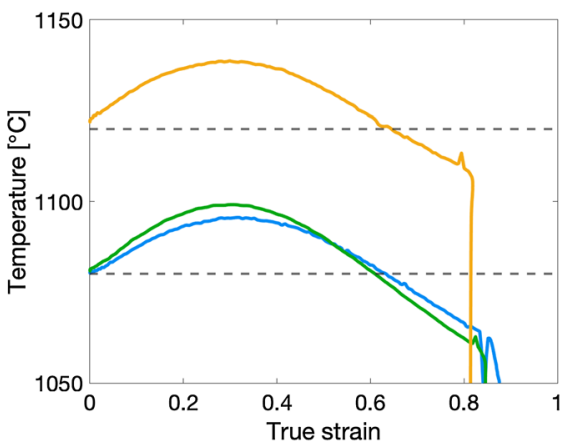

(e)

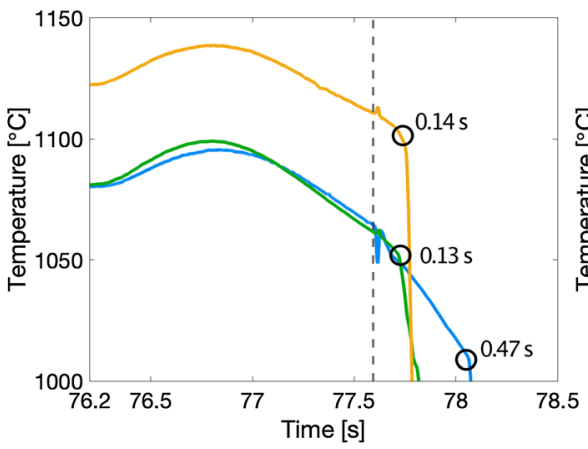

(h)

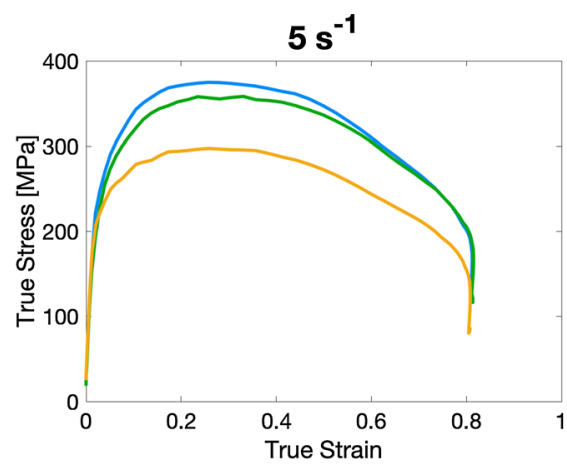

(c)

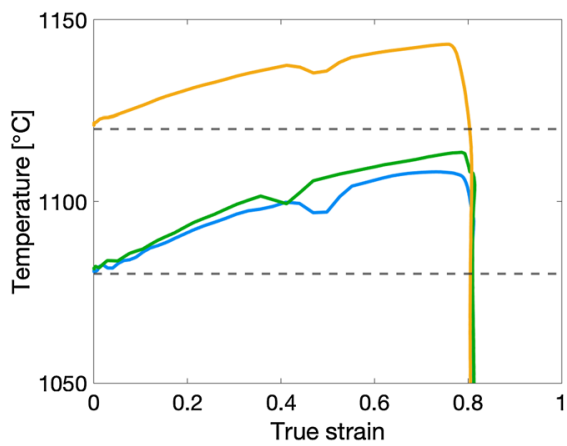

(f)

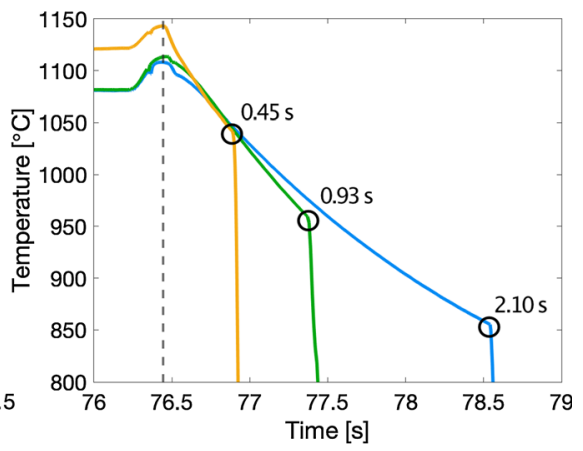

(i)

Fig. 4-Mechanical data for set C, set NC and set S. (a) to (c) show true stress-true strain data for $0.05 \mathrm{~s}^{-1}, 0.5$ second $^{-1}$ and 5 seconds ${ }^{-1}$ respectively. $(d)$ to $(f)$ show true strain vs temperature. Horizontal dashed lines mark the target temperatures of $1080{ }^{\circ} \mathrm{C}$ and $1120{ }^{\circ} \mathrm{C} .(g)$ to $(i)$ show temperature over time during deformation for each strain rate. Vertical lines in (g) to (i) mark end of deformation, circles mark initiation of the water quench and the numbers indicate the quench delay (time between end of deformation and start of quench) for each sample. Note that (g) only shows the last part of the test.

(d-f) are from samples in set NC. All images are captured somewhere in the central region, i.e., within the area from where the IPF maps in Figure 5 are acquired. Remnants of what could be prior grain boundaries are visible after deformation at the two higher strain rates from set C, Figures 7(b) and (c), with some grain boundary carbides still located at these prior boundaries. In Figure 7(c), the etched prior grain boundary runs through multiple recrystallized grains, while in 7 (b) these lines are visible both as boundaries between a deformed and recrystallized region (blue arrows), boundaries between two deformed regions (white arrows) and in entirely recrystallized regions (red arrows) seen in Figure 7(c). Lines of grain boundary carbides are also visible in the sample deformed at the slowest strain rate, Figure 7(a), however no etching of the grain boundaries regions could be observed in this condition, as they have for the higher strain rates. For 

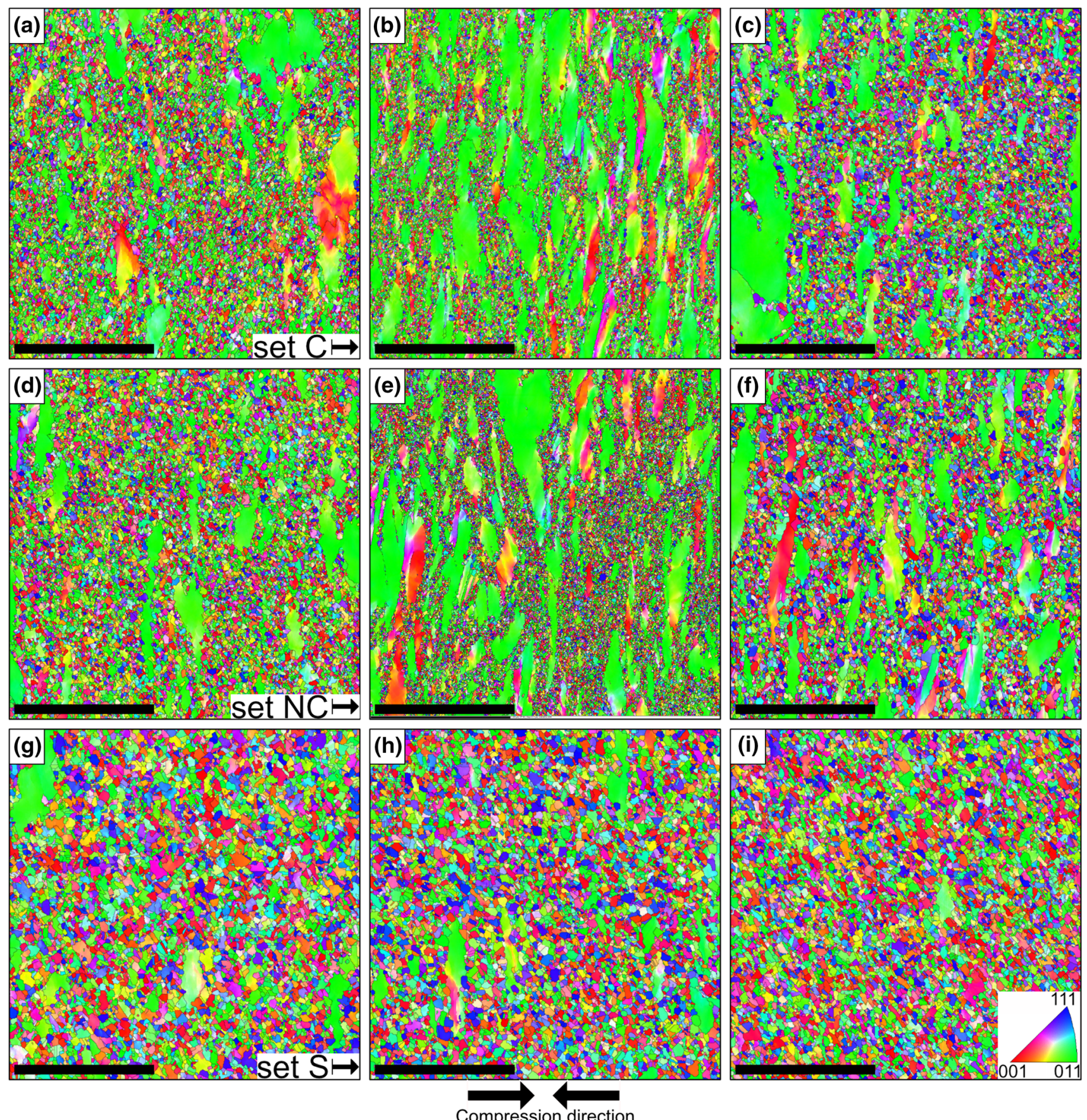

Compression direction

Fig. 5-IPF maps of the microstructures at the center of each sample quenched directly after deformation, coloring according to orientation parallel to deformation direction. Each column from left to right corresponds to samples deformed with a strain rate of $0.05 \mathrm{~s}^{-1}, 0.5 \mathrm{~s}^{-1}$ and 5 $\mathrm{s}^{-1}$ respectively. (a) to $(c)$ set C; $(d)$ to $(f)$ set NC. $(g)$ to $(i)$ set $\mathrm{S}$. The scale bar is $200 \mu \mathrm{m}$. 

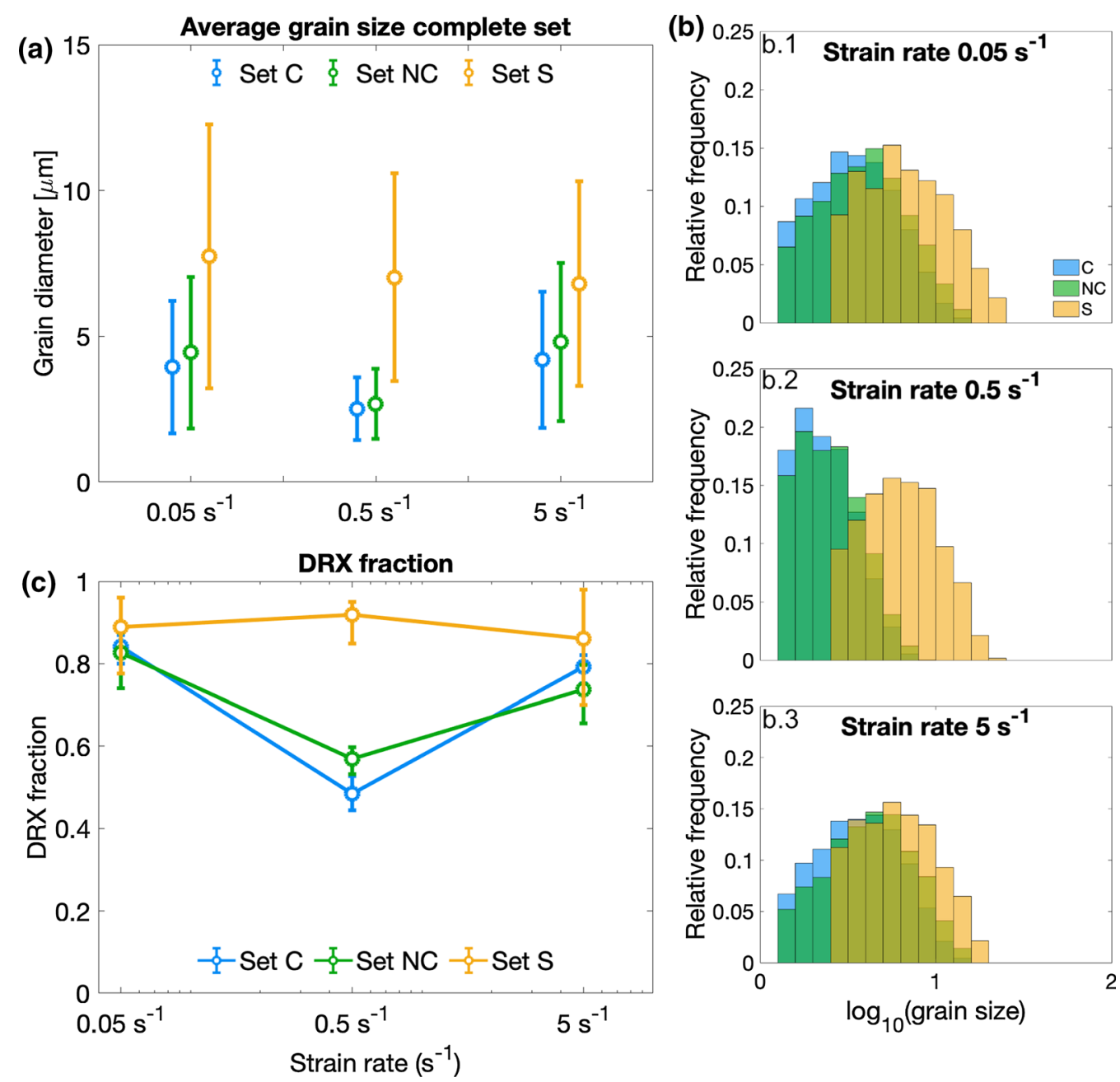

Fig. 6 - (a) Average grain size of recrystallized grains with standard deviation. (b) Relative frequency of $\log _{10}$ (grain size) for samples deformed at $0.05 \mathrm{~s}^{-1}$ (b.1), $0.5 \mathrm{~s}^{-1}$ (b.2) and $5 \mathrm{~s}^{-1}$ (b.3). (c) Recrystallized fraction at all strain rates for three deformation conditions.

set NC, Figures 7(d) through (f), only the strain rate of 0.5 second $^{-1}, 7(\mathrm{e})$ shows etched grain boundaries, but no carbides can be seen in them. The reason for the different behavior to the etching is unknown.

While many of the (presumably) prior grain boundaries still contained carbides, the amount appears to be significantly smaller and only isolated particles were seen, for set C [Figures 7(a) through (c)], as compared to the continuous coverage in the soaked sample, Figures 3(a) and (d), and none were observed for set NC [Figures 7(d) through (f)]. The remaining secondary carbides are associated with recrystallized regions in the microstructure. These observations suggest that carbides are indeed dissolved, either due to deformation or during the DRX process, even at temperatures below the carbide solvus.
Under the assumption that lines of grain boundary carbides seen in Figures 7(a) through (c) are outlines of original grain boundaries, it is clear the boundaries are left behind as the recrystallization front progresses into the grain interior. Any effect of the carbides on the DRX process is therefore expected to take place in the very early stage, where nucleation events are associated with the initial boundaries. At later stages nucleation will occur at the recrystallization front, which constitutes the boundary between deformed and undeformed material. The deformation levels investigated here resulted in a microstructure where dDRX has progressed to a degree where it was not possible to discern any contribution of the carbides on the nucleation stage from the microstructural observations. 

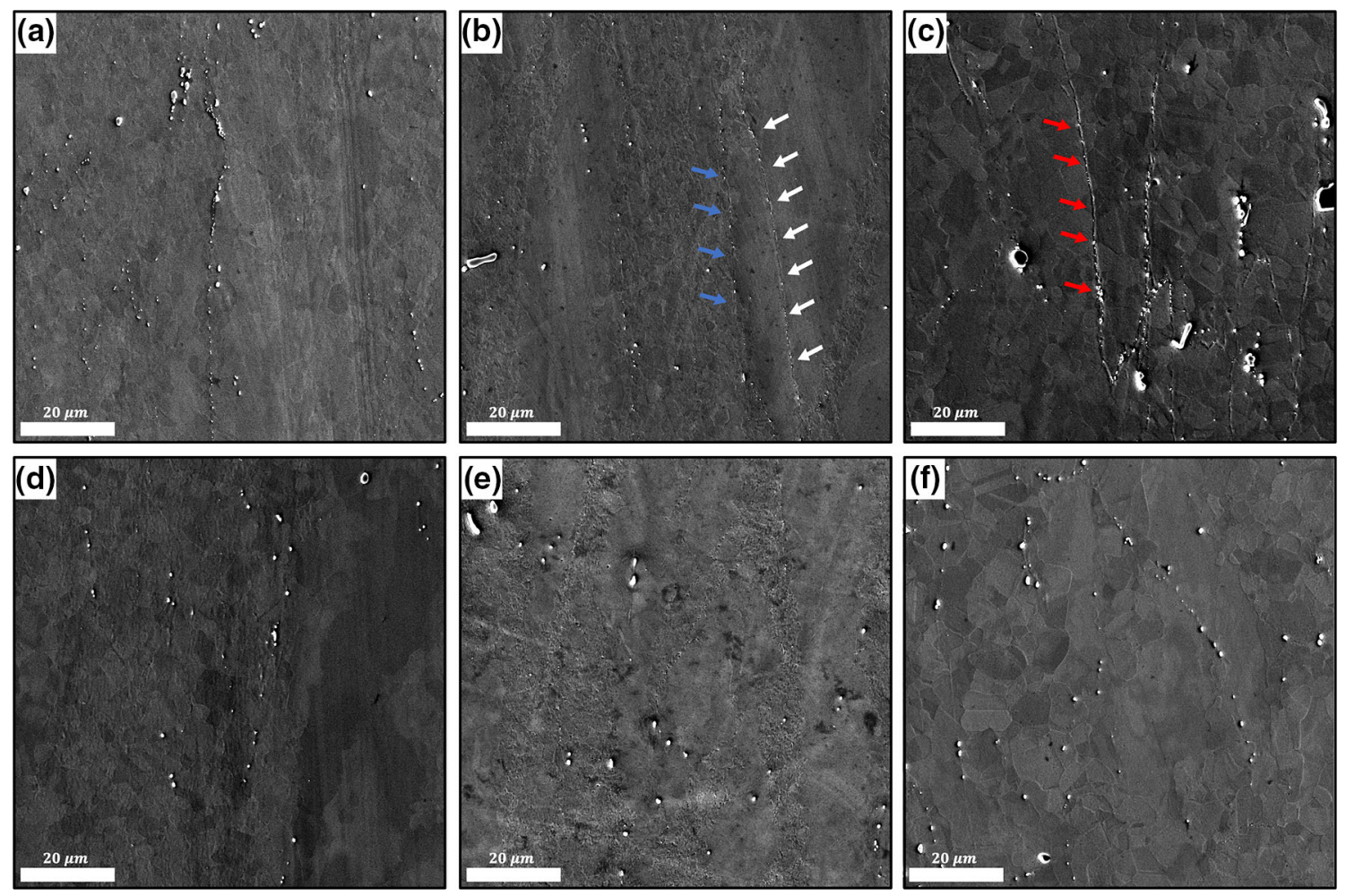

Fig. 7-SE images showing the grain boundary carbide distribution. (a) to (c) are from samples in set C deformed at $0.05 \mathrm{~s}^{-1}$ (a), $0.5 \mathrm{~s}^{-1}(b)$ and $5 \mathrm{~s}^{-1}$ (c). (d) to $(f)$ are of samples in set NC deformed at $0.05 \mathrm{~s}^{-1}(\mathrm{~d}), 0.5 \mathrm{~s}^{-1}(e)$ and $5 \mathrm{~s}^{-1}$ (f).

\section{ACKNOWLEDGMENTS}

This work was performed in part at the Chalmers Materials Analysis Laboratory, CMAL. Prof Joel Andersson at University West (Trollhättan Sweden) is kindly acknowledged for providing access to the Gleeble. Kjell Hurtig and Fabian Hanning are acknowledged for assistance with the Gleeble testing. Adrianna Lozinko at Chalmers University of Technology (Göteborg, Sweden) is acknowledged for her help with the muffle furnace.

\section{FUNDING}

Open access funding provided by Chalmers University of Technology.

\section{CONFLICT OF INTEREST}

The authors declare no conflict of interest.

\section{OPEN ACCESS}

This article is licensed under a Creative Commons Attribution 4.0 International License, which permits use, sharing, adaptation, distribution and reproduction in any medium or format, as long as you give appropriate credit to the original author(s) and the source, provide a link to the Creative Commons licence, and indicate if changes were made. The images or other third party material in this article are included in the article's Creative Commons licence, unless indicated otherwise in a credit line to the material. If material is not included in the article's Creative Commons licence and your intended use is not permitted by statutory regulation or exceeds the permitted use, you will need to obtain permission directly from the copyright holder. To view a copy of this licence, visit http://creat ivecommons.org/licenses/by/4.0/.

\section{REFERENCES}

1. R.C. Reed: The Superalloys : Fundamentals and Applications, Cambridge University Press, Cambridge, UK, 2006.

2. K. Huang and R. Logé: Mater. Des., 2016, vol. 111, pp. 548-74, https://oi.org/10.1016/j.matdes.2016.09.012.

3. T. Sakai, A. Belyakov, R. Kaibyshev, H. Miura, and J.J. Jonas: Prog. Mater. Sci., 2014, vol. 60, pp. 130-207, https://doi.org/ 10.1016/j.pmatsci.2013.09.002.

4. R. Doherty, D. Hughes, F. Humphreys, J. Jonas, D. Jensen, M. Kassner, W. King, T. McNelley, H. McQueen, and A. Rollett: Mater. Sci. Eng. A, 1997, vol. 238 (2), pp. 219-74, https://doi.org/ 10.1016/S0921-5093(97)00424-3.

5. E.V. Pereloma, P. Mannan, G. Casillas, and A.A. Saleh: Mater. Charact., 2017, vol. 125, pp. 94-98, https://doi.org/10.1016/ j.matchar.2017.01.026.

6. S. Gourdet and F. Montheillet: Mater. Sci. Eng. A, 2000, vol. 283 (1), pp. 274-88, https://doi.org/10.1016/S0921-5093(00)00733-4.

7. S.L. Semiatin, K.E. McClary, A.D. Rollett, C.G. Roberts, E.J. Payton, F. Zhang, and T.P. Gabb: Metall. Mater. Trans. A, 2013, vol. 44A (6), pp. 2778-98, https://doi.org/10.1007/s11661013-1675-1.

8. Y.C. Lin and X.M. Chen: Mater. Des., 2011, vol. 32 (4), pp. 1733-59, https://doi.org/10.1016/j.matdes.2010.11.048. 
9. H. Zhang, H. Zhou, S. Qin, J. Liu, and X. Xu: Mater. Sci. Eng. A, 2017, vol. 696, pp. 290-98, https://doi.org/10.1016/ j.msea.2017.04.077.

10. Y.C. Lin, J. Deng, Y.Q. Jiang, D.X. Wen, and G. Liu: Mater. Des., 2014, vol. 55, pp. 949-57, https://doi.org/10.1016/ j.matdes.2013.10.071.

11. R.L. Higginson, M. Aindow, and P.S. Bate: Mater. Sci. Eng. A, 1997, vol. 225 (1-2), pp. 9-21, https://doi.org/10.1016/s09215093(96)10571-2.

12. S.L. Semiatin, D.S. Weaver, R.C. Kramb, P.N. Fagin, M.G. Glavicic, R.L. Goetz, N.D. Frey, and M.M. Antony: Metall. Mater. Trans. A, 2004, vol. 35A (2), pp. 679-93, https://doi.org/ 10.1007/s11661-004-0379-y.
13. L. Pike, (2008), pp. 191-200. https://doi.org/10.7449/2008/Supera 1loys_2008_191_200.

14. C. Joseph, C. Persson, and M. Hörnqvist Colliander: Metall. Mater. Trans. A, 2020, vol. 51A (12), pp. 6136-41, https://doi.org/ 10.1007/s11661-020-06019-1.

15. M. Lapera, D. Spader, and H. Ghonem: Mater. Sci. Eng. A, 2020, vol. 769, p. 138421, https://doi.org/10.1016/j.msea.2019.138421.

16. E. Eriksson and M. Hörnqvist Colliander: Metals, 2021, vol. 11, p. 122, https://doi.org/10.3390/met11010122.

Publisher's Note Springer Nature remains neutral with regard to jurisdictional claims in published maps and institutional affiliations. 